\title{
Article \\ Ultrasound-Assisted Preparation of Mo/ZSM-5 Zeolite Catalyst for Non-Oxidative Methane Dehydroaromatization
}

\author{
Heidy Ramirez-Mendoza ${ }^{1,2}$, Mafalda Valdez Lancinha Pereira ${ }^{2}$, Tom Van Gerven ${ }^{1}{ }^{1}$, Cécile Lutz ${ }^{2}$ \\ and Ignacio Julian $3,4, *$ (D) \\ 1 Department of Chemical Engineering, KU Leuven, Celestijnenlaan 200F, 3001 Leuven, Belgium; \\ heidy.ramirez@arkema.com (H.R.-M.); tom.vangerven@kuleuven.be (T.V.G.) \\ 2 Service Adsorption, Groupement de Recherche de Lacq, ARKEMA France, BP34, 64170 Lacq, France; \\ mafalda.valdez@arkema.com (M.V.L.P.); cecile.lutz@arkema.com (C.L.) \\ 3 Instituto de Nanociencia y Materiales de Aragón (INMA) and Department of Chemical and Environmental \\ Engineering, University of Zaragoza, 50018 Zaragoza, Spain \\ 4 Networking Research Center on Bioengineering, Biomaterials and Nanomedicine (CIBER-BBN), \\ 28029 Madrid, Spain \\ * Correspondence: ijulian@unizar.es
}

check for

updates

Citation: Ramirez-Mendoza, H.; Valdez Lancinha Pereira, M.; Van Gerven, T.; Lutz, C.; Julian, I.

Ultrasound-Assisted Preparation of Mo/ZSM-5 Zeolite Catalyst for Non-Oxidative Methane Dehydroaromatization. Catalysts 2021, 11, 313. https://doi.org/10.3390/ catal11030313

Academic Editor: Narendra Kumar

Received: 31 January 2021

Accepted: 23 February 2021

Published: 27 February 2021

Publisher's Note: MDPI stays neutral with regard to jurisdictional claims in published maps and institutional affiliations.

Copyright: (c) 2021 by the authors. Licensee MDPI, Basel, Switzerland. This article is an open access article distributed under the terms and conditions of the Creative Commons Attribution (CC BY) license (https:/ / creativecommons.org/licenses/by/ $4.0 /)$.

\begin{abstract}
The activity and selectivity of Mo/ZSM-5, benchmarking catalyst for the non-oxidative dehydroaromatization of methane, strongly depend on the cluster size, spatial distribution, and chemical environment of the Mo-based active sites. This study discloses the use of an ultrasoundassisted ion-exchange (US-IE) technique as an alternative Mo/ZSM-5 synthesis procedure in order to promote metal dispersion along the zeolite framework. For this purpose, a plate transducer $(91.8 \mathrm{kHz})$ is employed to transmit the ultrasonic irradiation (US) into the ion-exchange reactor. The physico-chemical properties and catalytic activity of samples prepared under the said irradiation procedure and traditional impregnation (IWI) method are critically evaluated. Characterization results suggest that US neither affects the crystalline structure nor the particle size of the parent zeolite. However, US-IE promotes molybdenum species dispersion, avoids clustering at the external fresh zeolite surface and enhances molybdate species anchoring to the zeolite framework with respect to IWI. Despite the improved metal dispersion, the catalytic activity between catalysts synthesized by US-IE and IWI is comparable. This suggests that the sole initial dispersion enhancement does not suffice to boost the catalyst productivity and further actions such ZSM-5 support and catalyst pre-conditioning are required. Nevertheless, the successful implementation of US-IE and the resulting metal dispersion enhancement pave the way toward the application of this technique to the synthesis of other dispersed catalysts and materials of interest.
\end{abstract}

Keywords: methane aromatization; Mo/ZSM-5; ultrasound-assisted ion exchange; metal dispersion

\section{Introduction}

The drastic rise in shale gas production, the enormous proven reserves of natural gas, and the lack of mature sustainable alternatives to fulfil the worldwide increasing energy demand point to methane as the primary source for energy and chemicals in the near future [1-3]. The activation of such a stable molecule becomes the cornerstone of any valorization process devoted to transform methane into liquid fuels to ease its transportation into the end-users. Among the direct transformation routes, the direct one-step non-oxidative dehydroaromatization of methane (MDA) attracted much attention [4-12]. MDA tackles the direct conversion of $\mathrm{CH}_{4}$ into $\mathrm{CO}_{\mathrm{x}}$-free aromatics and olefins such as benzene, naphthalene, and ethylene as well as hydrogen [13]. Since the first report of this catalytic reaction in 1993 [14], many studies claimed that metal-supported ZSM-5 catalysts provide an effective shape-selective environment for methane conversion into benzene and naphthalene. Nevertheless, this aluminosilicate is rapidly deactivated by coke 
formation in the presence of methane at high temperatures $\left(>650^{\circ} \mathrm{C}\right)$ which otherwise are required to produce aromatics in a relevant amount, since MDA is strongly limited by the thermodynamic equilibrium [15-17]. In consequence, the catalytic activity and selectivity toward light aromatics decrease.

For MDA, the presence of molybdenum anchored at the zeolite structure (Mo/ZSM-5) is required to provide relevant conversion and selectivity $[18,19]$. However, the arrangement and dispersion of molybdenum species can influence the performance and durability of the catalyst. The presence of large molybdenum oxides $\left(\mathrm{MoO}_{\mathrm{x}}\right)$ aggregates or Mo clusters on the zeolite surface is reported to be unfavorable since they partially block the zeolite channels and favor the formation of coke deposits and catalyst deactivation. On the other hand, good molybdenum dispersion within the zeolite channels is claimed to retard the coke formation and deposition on the active sites, as well as to inhibit the blocking of pores [20,21].

Although the MDA reaction mechanism is not fully understood, there is a wide agreement on the fact that MDA is initiated by the pre-carburization of these $\mathrm{MoO}_{\mathrm{x}}$ sites into Mo oxycarbides $\left(\mathrm{MoO}_{\mathrm{x}} \mathrm{C}_{\mathrm{y}}\right)$ and/or Mo carbides $\left(\mathrm{Mo}_{2} \mathrm{C}\right)$, according to Equation (1). These carbides promote the activation of methane molecules, which subsequently undergo a series of coupling reactions to produce mainly $C_{6}$ and $C_{10}$ aromatics as well as $C_{2}$ species owing to the shape-selectivity of the ZSM- 5 zeolite $[17,20]$. The global reactions for ethylene, benzene, and naphthalene production from methane under non-oxidative conditions are depicted in Equations (2) to (4).

$$
\begin{gathered}
6 \mathrm{CH}_{4}+2 \mathrm{MoO}_{3} \rightarrow 12 \mathrm{H}_{2}+\mathrm{Mo}_{2} \mathrm{C}+6 \mathrm{CO}+\mathrm{C} \\
6 \mathrm{CH}_{4} \stackrel{\mathrm{Mo}_{2} \mathrm{C}}{\longrightarrow} \mathrm{C}_{6} \mathrm{H}_{6}+9 \mathrm{H}_{2} \\
2 \mathrm{CH}_{4} \stackrel{\mathrm{Mo}_{2} \mathrm{C}}{\longrightarrow} \mathrm{C}_{2} \mathrm{H}_{4}+2 \mathrm{H}_{2} \\
10 \mathrm{CH}_{4} \stackrel{\mathrm{Mo}_{2} \mathrm{C}}{\longrightarrow} \mathrm{C}_{10} \mathrm{H}_{8}+16 \mathrm{H}_{2}
\end{gathered}
$$

The physico-chemical and catalytic properties of the Mo/ZSM- 5 based catalysts are influenced by the preparation method, which plays a role in the final distribution, loading, and coordination of the metal species [22,23]. Typically, Mo/ZSM-5 is prepared by incipient wetness impregnation (IWI) of the zeolite with a solution of the ammonium heptamolybdate $\left(\left(\mathrm{NH}_{4}\right)_{6} \mathrm{Mo}_{7} \mathrm{O}_{24} \cdot \mathrm{H}_{2} \mathrm{O}\right)$ precursor, followed by calcination in air at $550{ }^{\circ} \mathrm{C}$. At this temperature, the heptamolybdates adopt a cationic form $\left(\left[\mathrm{Mo}_{2} \mathrm{O}_{5}\right]^{2+}\right)$ and anchor at the zeolite exchange sites. The maximum molybdenum loading in the cationic form will depend on the $\mathrm{Si} / \mathrm{Al}$ ratio of the zeolite. If the molybdenum loading is very low, many acid sites will remain without exchanging, resulting in a high acidity of the catalyst and faster deactivation. On the contrary, the Mo loading excess will result in the formation of $\mathrm{MoO}_{3}$ aggregates at the catalyst surface, leading to pore blocking, shape-selectivity worsening, and acceleration of catalyst deactivation. The optimal molybdenum loading was reported to be in the range of 3-6 wt. \% for ZSM-5 structured supports with Si / Al ratios around 20 [17]. Under the above mentioned IWI experimental conditions and using controlled temperature ramps, reasonably good metal dispersion has been obtained. Nevertheless, the deactivation rates are still high and the fine control of the dispersion is rather limited $[15,24]$. In an attempt to enhance the metal dispersion, to improve the catalytic activity and to reduce coking of Mo/ZSM- 5 catalysts, different strategies have been reported. Sun et al. [25] improved the dispersion of molybdenum oxide by adding ammonia to the aqueous solution of ammonium heptamolybdate prior to the impregnation process. Song et al. [26] described a hydrothermal post-synthesis treatment of commercial ZSM-5 in an aqueous solution of $\mathrm{Al}\left(\mathrm{NO}_{3}\right)_{3}$ to create uniform porous network that facilitates the access of the molybdenum species into the channels. Julian et al. [27] prepared Mo/ZSM-5 catalysts by changing the classical molybdenum salt precursor by polyoxomolybdate anions (POM). They demonstrated an enhanced metal dispersion on the aluminosilicate support at lower 
loading and more active and selective catalysts prepared with POM, which was key to partially suppress catalyst coking and improve stability. Furthermore, the same research group proposed a novel synthesis method for the same catalyst based on a solvothermal incorporation of molybdenum into the zeolite under supercritical conditions and reducing atmosphere [28]. The preparation method provided atom-like metal dispersion at the zeolite pores, resulting in a Mo/ZSM-5 catalyst with outstanding stability and the highest long-term hydrocarbon yield for MDA ( $8.9 \%$ after $15 \mathrm{~h}$ on stream).

Ultrasound has been reported as another alternative method for the preparation of metal-exchanged zeolites in order to enhance the dispersion of metallic species. Dantsin et al. [29] described a sonochemical preparation of $\mathrm{Mo}_{2} \mathrm{C} / \mathrm{ZSM}-5$ catalyst in which the reaction slurry was irradiated with a high-intensity ultrasound horn $\left(20 \mathrm{kHz}-\sim 80 \mathrm{~W} \cdot \mathrm{cm}^{-2}\right)$ for $3 \mathrm{~h}$ at $85^{\circ} \mathrm{C}$ under argon flow. The result was a bifunctional "eggshell" catalyst with a homogeneous distribution of $\mathrm{Mo}_{2} \mathrm{C}$ particles $(\sim 2 \mathrm{~nm})$ decorating the outside of the ZSM-5 zeolite. They claimed that the gas phase of the collapsing bubble is responsible for the formation of metal clusters. Ultrasound can control the formation of clusters on the outer surface of the zeolite crystals since the clusters are formed during acoustic cavitation inside a collapsing bubble. At lower frequencies, the size of bubbles is of the order of $100 \mu \mathrm{m}$, which is too large to take place within the micropores of a zeolite. Despite the homogeneous distribution of metallic particles, the catalytic activity for the aromatization of methane to benzene was quite comparable to other catalysts reported before.

Woo et al. [30] applied ultrasound during the ion-exchange of $\mathrm{CuY}$ zeolite catalyst by using a tip-probe sonicator (Sonics, Sonics \& Materials Inc., Newtown, CT, USA, 750 W) for various periods of time $(3,5,10,20$ and $30 \mathrm{~min})$ at $20 \%$ amplitude. The applied power was $150 \mathrm{~W}$. They observed that ultrasound enhanced the dispersion of active species by boosting their incorporation into the zeolite channels in a very short time. The enhanced dispersion of active species increased the number of active sites available for the oxidative carbonylation of methanol to dimethyl carbonate, resulting in an improved catalytic activity.

Kumar et al. [23] studied the influence of ultrasound irradiation during the in situ introduction of platinum in ZSM-5 zeolite. They used an autoclave with a high-power ultrasonic probe $(20 \mathrm{kHz}-60 \mathrm{~W})$ integrated through the bottom of the autoclave. The results showed a reduction of the crystal size of the catalysts prepared with ultrasound compared to the catalyst synthesized in the absence of ultrasound. The use of ultrasound during the preparation of the catalyst resulted in high conversion of n-pentane and high selectivity to iso-pentane (96\%) owing to the well dispersed platinum over small ZSM-5 zeolite crystals. Similarly, Vafaeian et al. [31] reported a Ni/ZSM-5 nanocatalyst prepared by ultrasound irradiation $(20 \mathrm{kHz}-90 \mathrm{~W})$ during $45 \mathrm{~min}$ in argon atmosphere. The effect of ultrasound was more pronounced at lower metal loadings (3\% and $8 \%$ ), resulting in smaller particle size and more homogeneous particle size distributions.

Another effect of ultrasound on the preparation of metal-exchanged zeolites corresponds to an enhanced exchange equilibrium. Erten-Kaya et al. [32] studied the ionexchange kinetics of $\mathrm{Li}^{+}, \mathrm{Ca}^{2+}$, and $\mathrm{Ce}^{3+}$ in zeolite $\mathrm{NaX}$. They observed that ultrasound did not accelerate the exchange of cations. However, the amount of cations exchanged at the equilibrium was higher when ultrasound was applied. Ultrasound is believed to act as a co-driving force of concentration of cations in solution, increasing the exchange amount during the ion-exchange process. A similar result was shown by Gerzeliev et al. [33] for the exchange of calcium and lanthanum in zeolite $\mathrm{NaX}$.

In the present study, ultrasound is applied to enhance the dispersion of the metal species during the preparation of Mo/ZSM- 5 catalyst by ion-exchange. The influence of the ultrasound treatment on the catalyst preparation and physico-chemical properties is investigated by X-ray fluorescence, argon adsorption, X-ray diffraction, Raman spectroscopy, and scanning and transmission electron microscopy. The impact of the preparation method on the catalytic activity is evaluated for the non-oxidative methane dehydroaromatization process. 


\section{Results and Discussion}

\subsection{Influence of Ultrasonic Irradiation on Physico-Chemical Properties}

The catalysts were characterized in order to evaluate the influence of ultrasonic irradiation on their physico-chemical properties. The metal concentration and textural properties are shown in Table 1 . The molybdenum concentrations were within the range of the targeted values irrespective of sonication. These metal loadings were selected according to the optimum molybdenum content reported (3-6 wt. \%) to promote aromatic productivity in the MDA process on ZSM- 5 supports [15,34].

Table 1. Summary of physical-chemical properties of the parent zeolite and the different Mo/ZSM-5 catalysts prepared with ultrasound (US) and without ultrasound (No US).

\begin{tabular}{|c|c|c|c|c|}
\hline Sample & $\begin{array}{c}\text { Theoretical wt. } \\
\text { \% Mo }\end{array}$ & wt. $\% \mathrm{Mo}^{\mathrm{a}}$ & $\begin{array}{l}\text { Surface Area } \\
\qquad\left(\mathrm{m}^{2} \cdot \mathrm{g}^{-1}\right)\end{array}$ & $\begin{array}{l}\text { Pore Volume } \\
\quad\left(\mathrm{cm}^{3} \cdot \mathrm{g}^{-1}\right)\end{array}$ \\
\hline H-ZSM-5 & - & - & 351 & 0.130 \\
\hline 5 wt. \%-US & 5.44 & 5.35 & 333 & 0.122 \\
\hline 5 wt. \%-No US & 5.44 & 5.35 & 338 & 0.120 \\
\hline 6 wt. \%-US & 6.50 & 6.39 & 310 & 0.113 \\
\hline 6 wt. $\%-N o$ US & 6.50 & 6.39 & 315 & 0.118 \\
\hline
\end{tabular}

a Weight percentage obtained by XRF analysis. ${ }^{\mathrm{b}}$ Specific surface area determined by $\mathrm{N}_{2}$ adsorption (BET method).

${ }^{\mathrm{c}}$ Total pore volume determined by $\mathrm{N}_{2}$ adsorption.

The use of ultrasound during the ion-exchange process did not enhance the exchange equilibrium, contrary to what was reported by Erten-Kaya et al. [32], where the amount of cations exchanged at the equilibrium $\left(\mathrm{Li}^{+}, \mathrm{Ca}^{2+}\right.$, and $\left.\mathrm{Ce}^{3+}\right)$ in zeolite $\mathrm{NaX}$ was higher when ultrasound was applied $(20 \mathrm{kHz}-500 \mathrm{~W})$. The surface area and the pore volume decreased as the metal load increased. This behavior upon introduction of molybdenum is related to the accumulation of molybdenum species formed during the calcination step, by decomposition of the precursor salt, that generates both saturation of the zeolite channels and partial blockage of the pores [20,27]. Besides, the ultrasonic irradiation did not significantly affect the textural properties. Whether ultrasound was applied or not, the surface area and pore volume are comparable.

The similarity of X-ray diffraction (XRD) patterns between the parent H-ZSM-5 zeolite and Mo/ZSM- 5 catalysts indicates that the crystalline structure of the zeolite remained unaltered after molybdenum loading (Figure 1). The peaks intensities are constant. The absence of peaks corresponding to $\mathrm{MoO}_{3}(27.3,33.7$ and 38.9 $)$ reveals that the samples do not contain $\mathrm{MoO}_{3}$ crystallites or, at least, they are very well dispersed and small along the zeolite channels. If present, the crystalline phases of $\mathrm{MoO}_{3}$ are below the detection limit of the equipment and do not show specific reflections. Furthermore, the use of ultrasound did not show influence on the crystalline structure after molybdenum loading.

Raman spectroscopy was performed to gain insight into the $\mathrm{MoO}_{\mathrm{x}}$ structures formed during the ion-exchange process by detecting the metal-oxide vibrational modes in the powder (Figure 2). All the samples showed a wide band at $376 \mathrm{~cm}^{-1}$ corresponding to the lattice vibration of the zeolite. Additionally, the broad band between 860 and $970 \mathrm{~cm}^{-1}$ can be attributed to the dimeric $\left(\mathrm{Mo}_{2} \mathrm{O}_{5}\right)^{2+}$ cations exchanged at the acid sites of the zeolite, within the pores. The peak at $970 \mathrm{~cm}^{-1}$ corresponds to $\mathrm{Mo}=\mathrm{O}$ stretching mode of the amorphous $\left(\mathrm{MoO}_{\mathrm{x}}\right)^{\mathrm{n}+}$ [27]. The greater intensity of this band in the samples prepared with ultrasound (see relative band intensity values, $\mathrm{I}_{970} / \mathrm{I}_{376}$ ) is attributed to the vibration of a greater number of molecular molybdate-support bonds for a given metal loading. This indicates an enhanced cationic exchange at the acid sites of the zeolite using the ultrasound synthesis method. Furthermore, the absence of bands at $300 \mathrm{~cm}^{-1}$ (Mo=O bending), 680 , $820 \mathrm{~cm}^{-1}$ (Mo-O-Mo stretching) and $1003 \mathrm{~cm}^{-1}$ (Mo=O stretching) confirmed the absence of $\mathrm{MoO}_{3}$ crystallites at the zeolite surface $[35,36]$. The detection of molybdenum species was possible by Raman spectroscopy due to the sensitivity of this characterization technique to metal-oxide vibrational modes. 


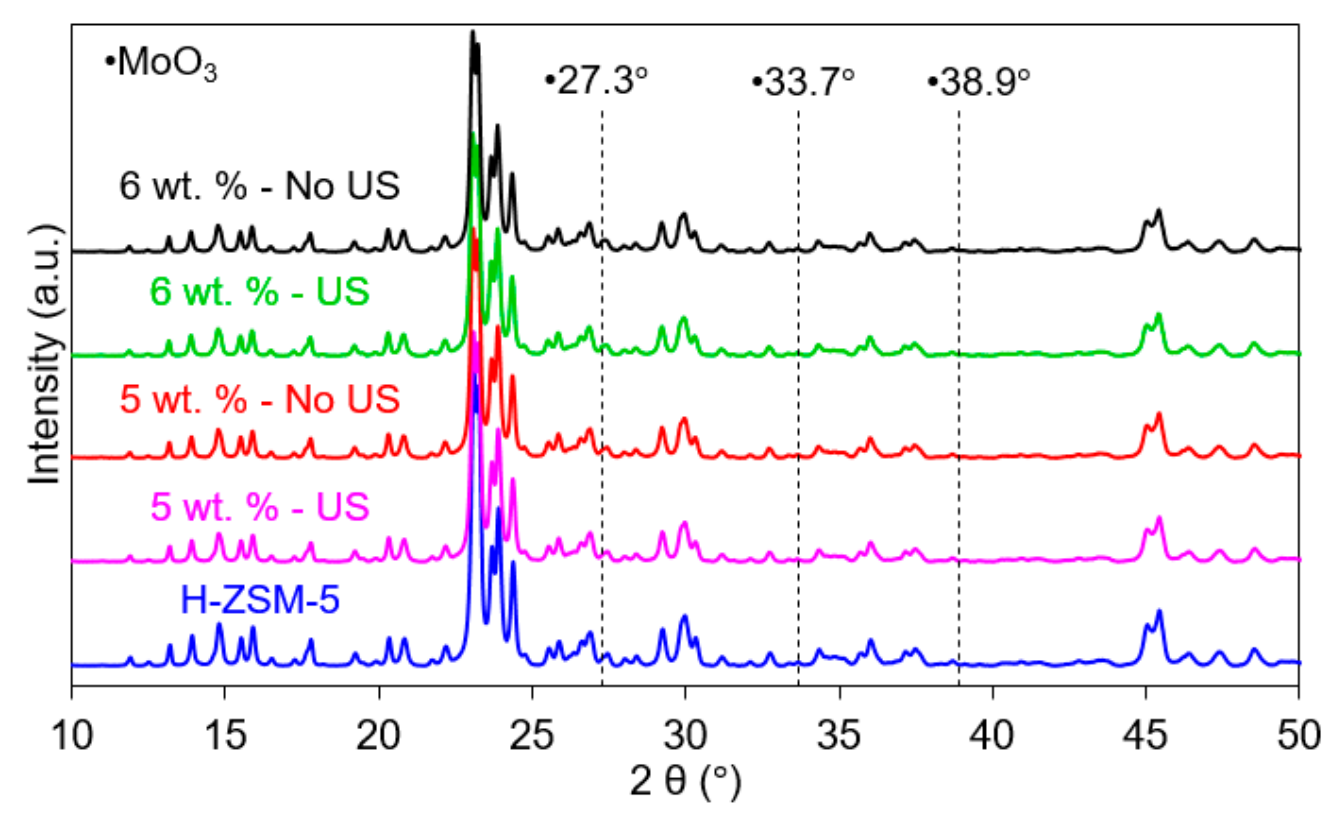

Figure 1. XRD patterns of H-ZSM-5 and Mo/ZSM-5 catalysts prepared by ion-exchange with ultrasound (US) and without ultrasound (No US).

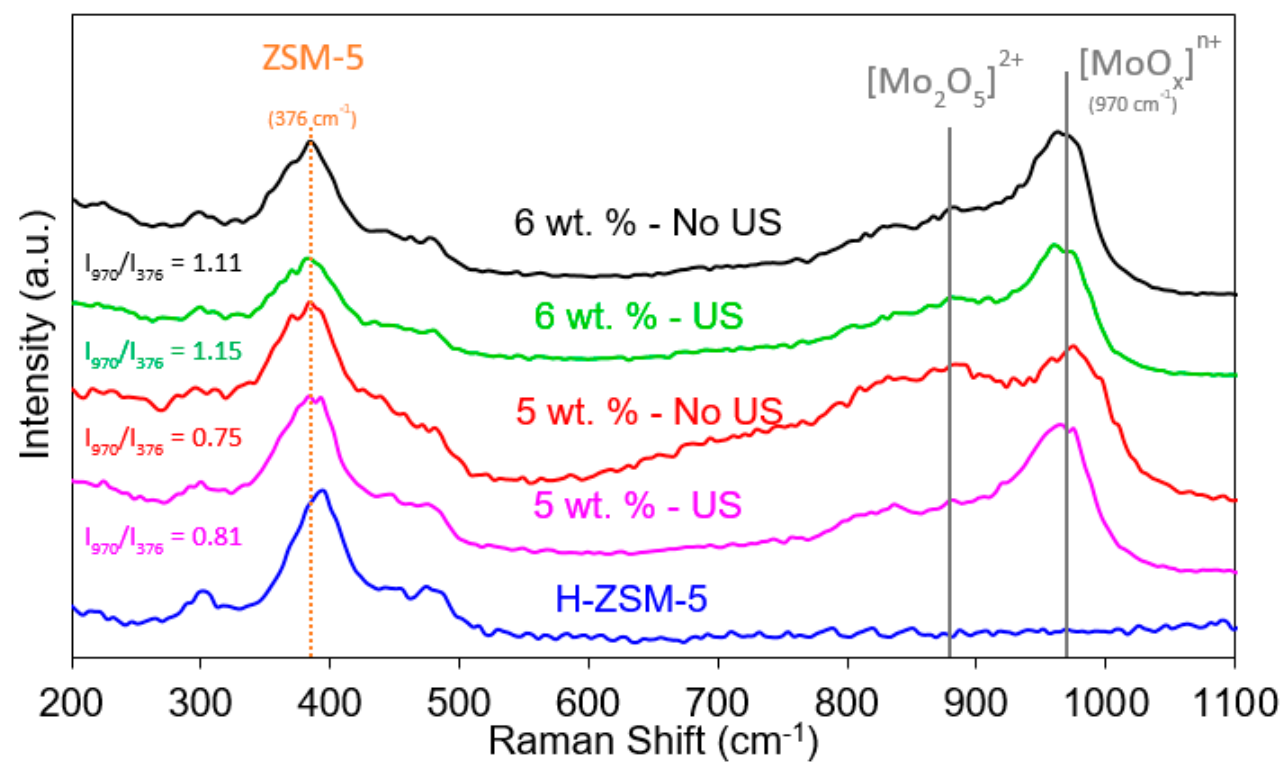

Figure 2. Raman spectra of H-ZSM-5 and Mo/ZSM-5 catalysts prepared by ion-exchange with ultrasound (US) and without ultrasound (No US).

Figure 3 shows the Scanning Electron Microscopy images (SEM-secondary electrons) of the parent zeolite and Mo/ZSM-5 catalysts containing a $6 \mathrm{wt}$. \% metal loading prepared with and without ultrasound. The morphology and particle size of the parent zeolite were not apparently modified neither by the addition of molybdenum, nor by the use of ultrasound during the ion-exchange process. In contrast, the analysis of backscattered electrons suggested that Mo species clustering and agglomeration at the zeolite surface occur preferentially for the samples that were not irradiated with ultrasound. The bright particles in Figure $4 \mathrm{a}, \mathrm{b}$ correspond to molybdenum species, since Mo has the highest atomic weight along the sample components. The bulk composition of the samples was confirmed by an Energy Dispersive X-ray detection (EDX) analysis (Figure 4c,d). Even if bright particles were not identified by SEM, the EDX analysis confirmed a concentration 
of $\sim 5.9 \mathrm{wt}$. \% Mo in the ultrasound-irradiated sample. These results suggest that the use of ultrasound may help to prevent a possible agglomeration of particles at the zeolite surface in Mo/ZSM-5 catalysts. This finding agrees with the previously discussed Raman results on the role of ultrasound in the enhancement of Mo species integration within the zeolite pores.
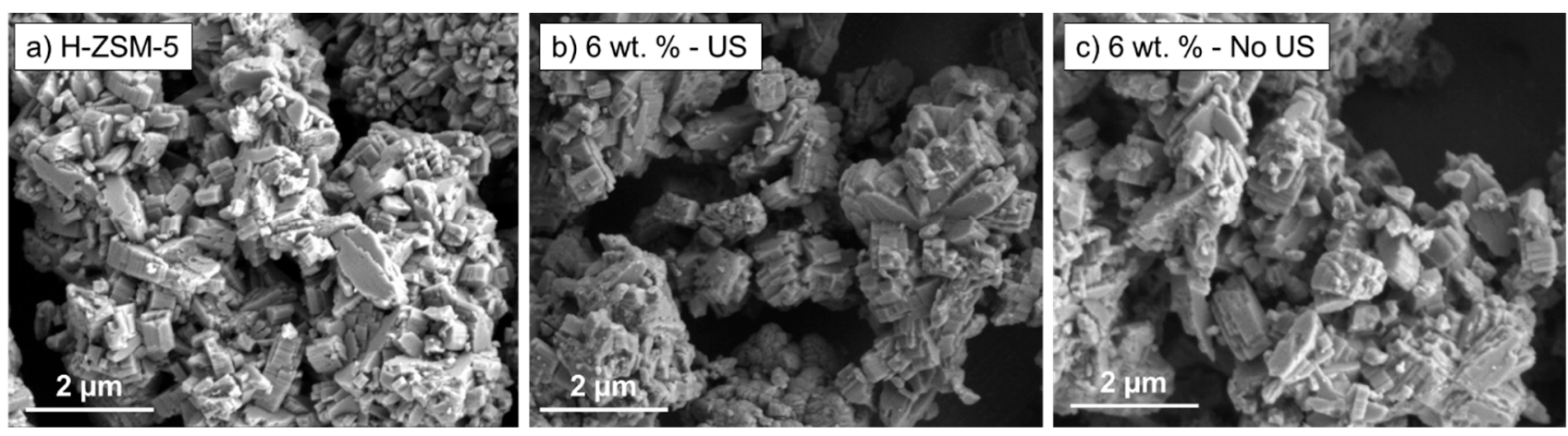

Figure 3. SEM images of the (a) parent zeolite H-ZSM-5 and Mo/ZSM-5 catalysts with 6 wt. \% loading prepared, (b) with ultrasound (US) and (c) without ultrasound (No US).
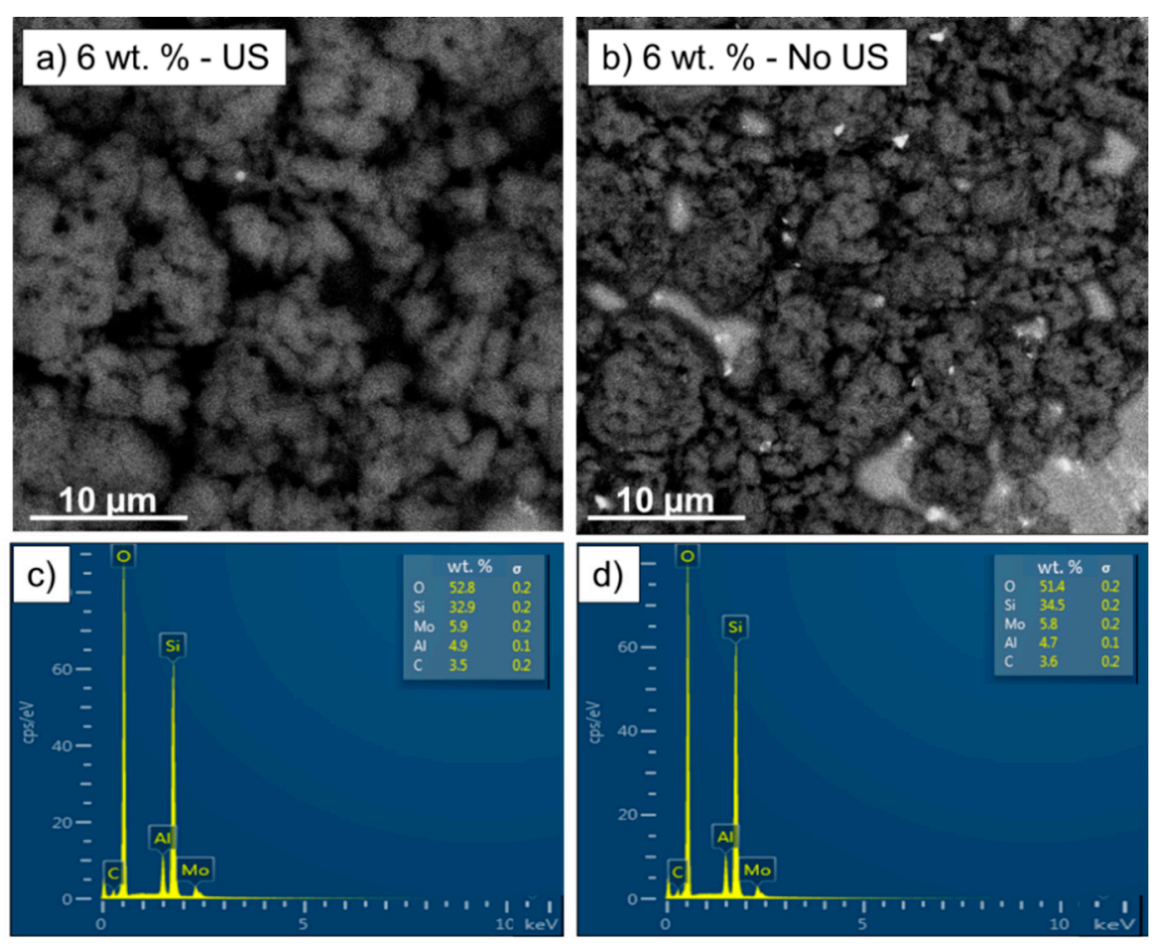

Figure 4. SEM images of Mo/ZSM-5 catalysts with $6 \mathrm{wt}$ \% loading prepared (a) with ultrasound (US) and (b) without ultrasound (No US) taken with the backscattered electron detector and (c,d) their corresponding EDX analysis.

In order to get further insight on the dispersion of molybdenum species on the zeolite structure, EDX mapping was performed on the Mo/ZSM- 5 catalyst $6 \mathrm{wt}$. \% prepared with ultrasound (Figure 5). The mapping confirmed the presence of the characteristic elements of the zeolite structure (i.e., silicon, aluminum, and oxygen) as well as molybdenum. Do note that the Al mapping highlights the presence of the sample holder (made of aluminum) in the background. In consequence, green color is detected in zones where the zeolite is not present. Finally, it is observed that the distribution of molybdenum was very homogeneous along the zeolite support (orange color on the mapping). 

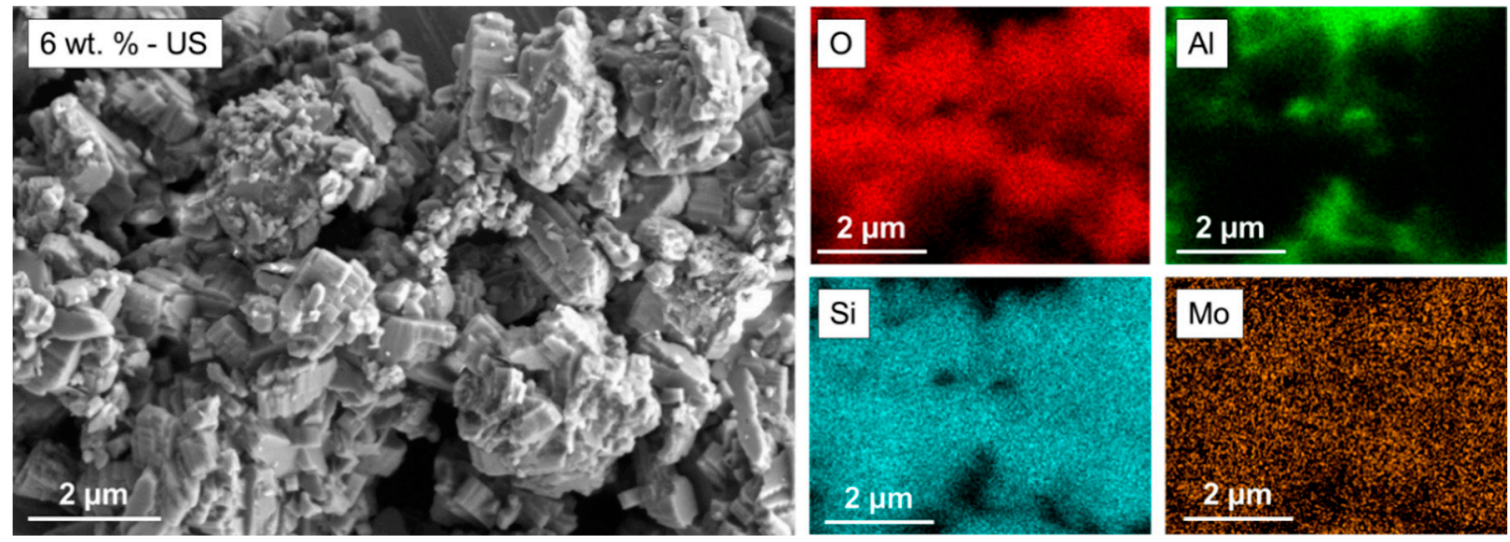

Figure 5. SEM image Mo/ZSM-5 catalyst 6 wt. \% prepared with ultrasound and its corresponding EDX mapping for O, Al, Si, and Mo.

The molybdenum dispersion was also evaluated by scanning-TEM (STEM). As it can be observed in Figure 6, the bright dots on the micrographs correspond to molybdenum species confirmed by the EDX analysis (Figure 6e). No agglomerates of $\mathrm{MoO}_{3}$ were identified along the external zeolite surface indicating a good dispersion of metal species on the zeolite. The size of bright dots ranges from $\sim 0.50-0.60 \mathrm{~nm}$ (indicated by the white lines) and the estimated pore size of ZSM- 5 zeolite is $0.54-0.56 \mathrm{~nm}$. Taking into account that the atomic radius of Mo is $0.21 \mathrm{~nm}$, one can ensure that single atoms and 2-3 Mo particle clusters coexist within the zeolite pores. This observation is in agreement with the previous results in which the pore volume decreased by the incorporation of molybdenum and the metal species were not detected by XRD due to their small size. Ultrasound irradiation slightly enhanced the dispersion of molybdenum (Figure 6a,c) compared to the conventional ion-exchange method (Figure 6b,d). Mo clustering and Mo species accumulation were detected in some regions of the no-US samples, whereas they were not observed in the irradiated samples. The high metal dispersion in the $6 \mathrm{wt}$. \% Mo/ZSM-5 catalyst prepared with ultrasound is particularly remarkable (Figure 6c).

In order to quantify Mo dispersion, the atomic $\mathrm{Mo} /(\mathrm{Si}+\mathrm{Al})$ rates obtained by SEMEDX and X-ray Photoelectron Spectroscopy (XPS) for the four employed fresh catalysts were compared. Since SEM-EDX provides bulk atomic composition and XPS has low penetration and provides superficial compositions, the comparison between both values allows determining the extent of internalized Mo species within the zeolite pores with respect to that at the surface. Analogously, the $\mathrm{Si} / \mathrm{Al}$ rate obtained by both techniques allows determining the extent of dealumination of the zeolite support as a result of metal incorporation. Table 2 shows these two atomic rates as well as the obtained qualitative metal loadings by SEM-EDX. It is observed that the metal loadings obtained by the semiquantitative SEM-EDX slightly overestimate the values attained by XRF (Table 1). In spite of this, it is still possible to evaluate the role of the synthesis method and metal loading on the metal dispersion by coupling the results of both SEM-EDX and XPS techniques. The similarity between $\mathrm{Si} / \mathrm{Al}$ rates obtained by bulk and superficial techniques in case of USirradiated samples suggests that Mo incorporation to the zeolite does not lead to apparent zeolite dealumination and, thus, permanent damage of the zeolite structure. However, The $\mathrm{Si} / \mathrm{Al}$ decay detected by XPS for the non-irradiated samples suggests that $\mathrm{Al}$ has somehow migrated to the zeolite surface, probably in the form of inactive and detrimental Mo aluminates. Regarding the $\mathrm{Mo} /(\mathrm{Si}+\mathrm{Al})$ rates of the evaluated samples, the atomic Mo content at the surface of all catalysts is $4-5$ times greater than the bulk Mo content, suggesting that an important fraction of the incorporated Mo remains un-internalized within the zeolite pores. Nevertheless, it is confirmed that the samples pre-treated with US-radiation provide a better Mo internalization within the pores (i.e., lower $\mathrm{Mo} /(\mathrm{Si}+\mathrm{Al})$ as measured by XPS) and, thus, better dispersion. 

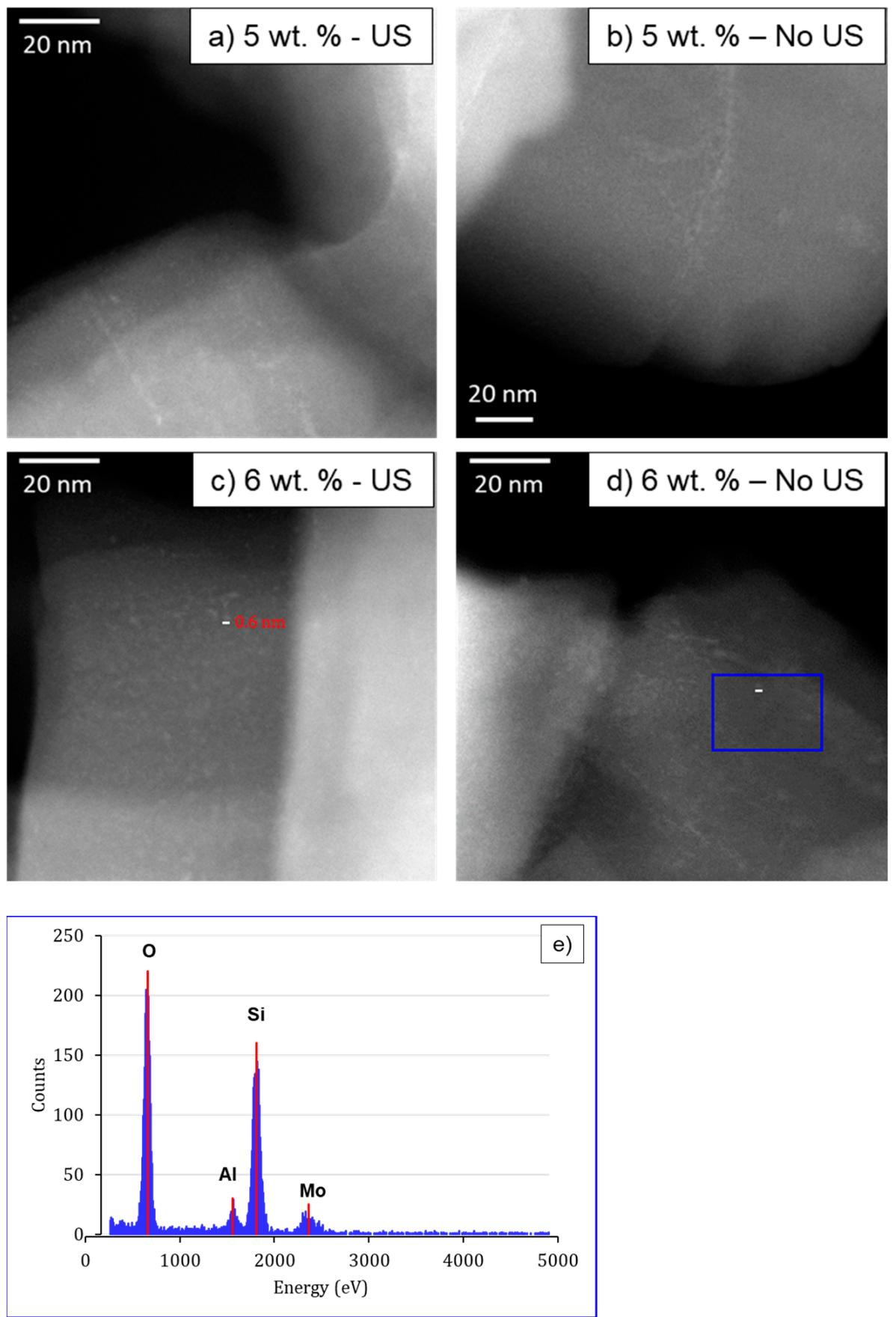

Figure 6. STEM micrographs of Mo/ZSM-5 catalyst prepared by ion-exchange $(\mathbf{a}, \mathbf{c})$ with ultrasound (US) and (b,d) without ultrasound (No-US). (e) EDX analysis of Mo/ZSM-5 catalyst 6 wt. \% prepared with ultrasound.

Table 2. SEM-EDX and XPS characterization of the atomic composition and metal loading for fresh catalysts.

\begin{tabular}{cccccc}
\hline Sample & $\begin{array}{c}\text { Mo (wt. \%) } \\
\text { SEM-EDX }\end{array}$ & $\begin{array}{c}\text { Si/Al } \\
\text { SEM-EDX }\end{array}$ & $\begin{array}{c}\text { Si/Al } \\
\text { XPS }\end{array}$ & $\begin{array}{c}\text { Mo/(Si + Al) } \\
\text { SEM-EDX }\end{array}$ & $\begin{array}{c}\text { Mo/(Si + Al) } \\
\text { XPS }\end{array}$ \\
\hline 5 wt. \%-US & $5.0 \pm 0.7$ & 13.7 & 14.1 & 0.03 & 0.15 \\
5 wt. \%-No US & $5.2 \pm 0.7$ & 14.1 & 11.9 & 0.03 & 0.22 \\
6 wt. \%-US & $5.8 \pm 0.8$ & 14.3 & 14.1 & 0.04 & 0.16 \\
6 wt. \%-No US & $5.9 \pm 0.7$ & 14.3 & 12.5 & 0.04 & 0.17 \\
\hline
\end{tabular}




\subsection{Influence of Ultrasonic Irradiation on the Catalytic Activity}

The catalytic activity of the Mo/ZSM- 5 catalysts for non-oxidative methane dehydroaromatization was evaluated under the experimental conditions described in Section 3.4. Methane conversion, overall hydrocarbon yield, and yield of the major product of interest, i.e., benzene, are shown in Figure 7. The MDA catalytic activity of the four catalysts after $4 \mathrm{~h}$ on stream is shown in Table 3.
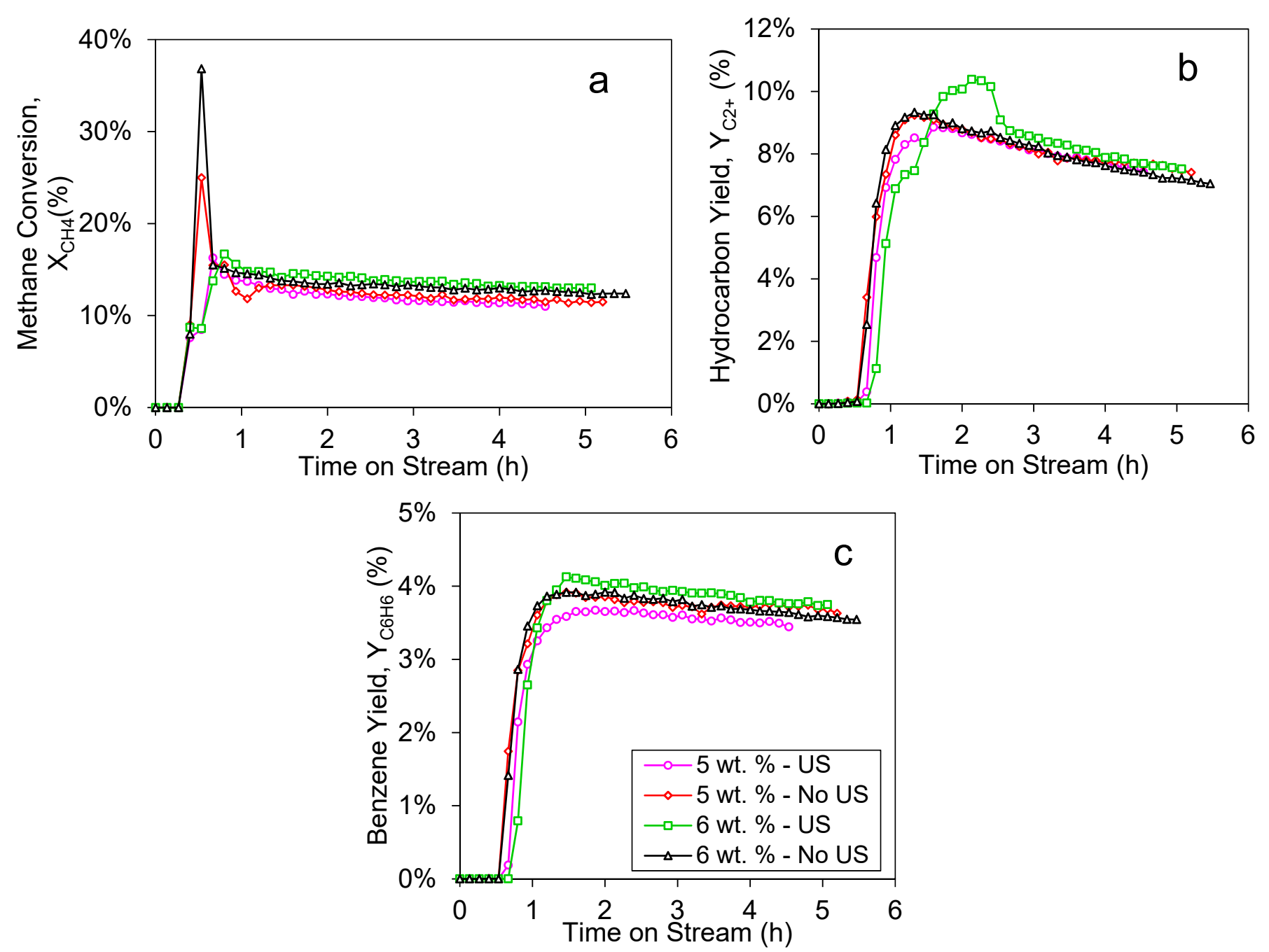

Figure 7. (a) Methane conversion, (b) overall hydrocarbon yield, and (c) benzene yield for Mo/ZSM-5 catalysts prepared by ion-exchange with ultrasound (US) and without ultrasound (No US).

Table 3. Catalytic activity of the Mo/ZSM-5 catalysts prepared with and without ultrasound for non-oxidative methane dehydroaromatization after $4 \mathrm{~h}$ on stream.

\begin{tabular}{cccc}
\hline Sample & $\mathbf{X}_{\mathrm{CH} 4-4 h}(\%)$ & $\mathbf{Y}_{\mathrm{C} 2+}(\%)$ & $\mathbf{Y}_{\mathbf{C} 6 \mathrm{H} 6-4 h}$ (\%) \\
\hline 5 wt. \%-US & 12.0 & 7.8 & 3.5 \\
5 wt. \%-No US & 11.4 & 7.7 & 3.7 \\
6 wt. \%-US & 13.2 & 7.9 & 3.8 \\
6 wt. \%-No US & 13.0 & 7.6 & 3.7 \\
\hline
\end{tabular}

The small differences in the MDA performance may be attributed, first, to the metal loading and, second, to the different accessibility of methane to the molybdenum sites, which depends on the molybdenum dispersion on the support. The samples prepared without ultrasound show a very high initial catalytic activity, which was higher for the 
$6 \mathrm{wt}$ \% loading, as expected. This behavior may be attributed to the presence of regions with a greater concentration of molybdenum species on the surface of the zeolite in the noUS samples (Figure $4 b$ ). These bigger agglomerates are more exposed to the reaction stream and, thus, to the faster formation of active $\mathrm{Mo}_{\mathrm{x}} \mathrm{O}_{\mathrm{y}} \mathrm{C}_{\mathrm{z}}$ species via $\mathrm{MoO}_{\mathrm{x}}$ carburization along the induction period. As a result of the poorer dispersion, the catalytic activity of the no-US samples rapidly decayed beyond that of the $6 \%$ wt.-US sample due to their more intense coking. In the case of samples prepared with ultrasound, the methane conversion did not show a peak of high conversion during the first hour on stream (Figure 7a), indicating a softer carburization of evenly dispersed Mo sites along the support.

The smooth decay of benzene yield over time attained for every sample (Figure 7c) can be attributed to the progressive loss of shape-selectivity within the zeolite pores by coke deposition. As a result, the reaction progress leads to a reduced contact time with the active sites and, thus, to an increased production of $C_{2}$ species.

The transient products distribution of $6 \mathrm{wt}$. \% Mo/ZSM-5 catalyst prepared with ultrasound is depicted in Figure 8. Unreacted methane, naphthalene, ethylene, and benzene, small amount of ethane, and toluene were detected at the outlet gas of the MDA process. As previously discussed, the coke detected during the first minutes of reaction is attributed to the presence of $\mathrm{Mo}_{2} \mathrm{C}$ formed during the induction period as a result of the reduction of molybdenum oxide species. The coke selectivity increase after two hours on stream can be related with the parallel formation pre-graphitic coke from polyaromatic hydrocarbons (hard coke), apart from the graphitic coke formed at the oxycarbide active sites (soft coke) [28].

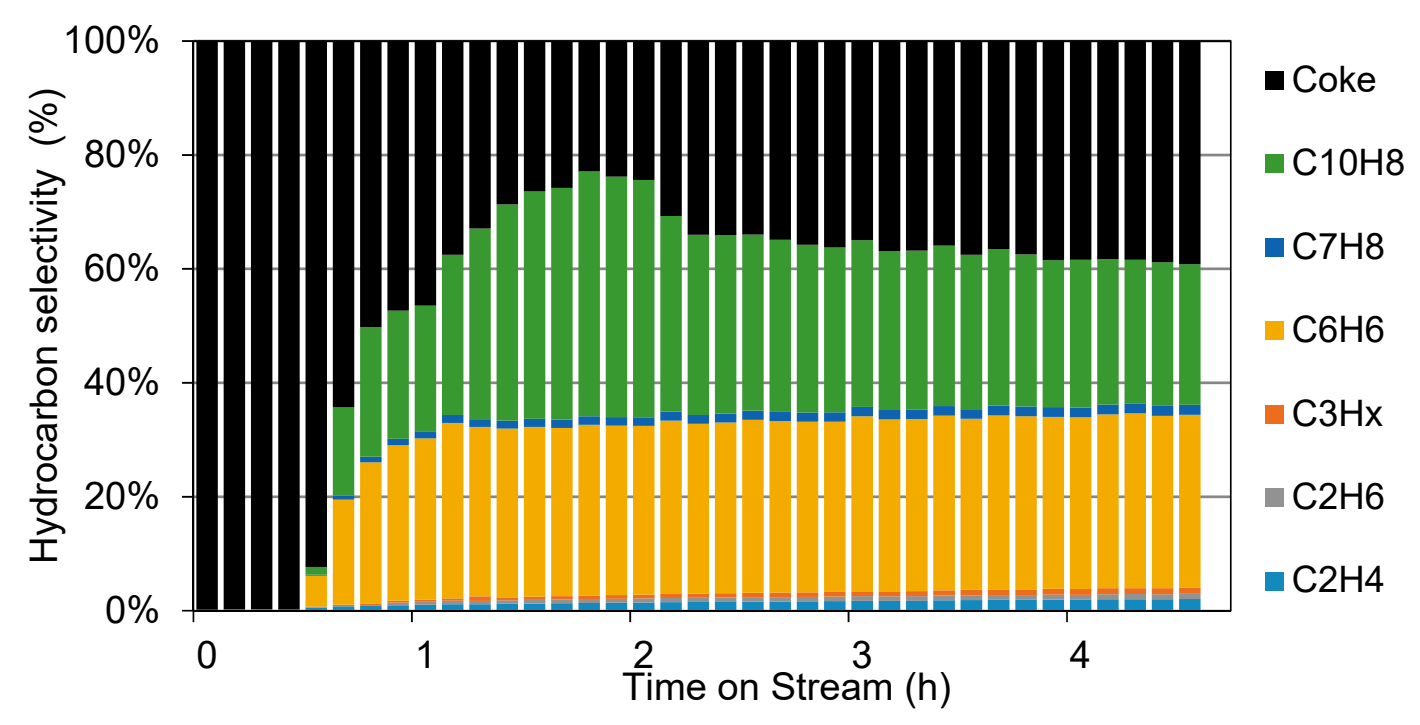

Figure 8. Experimental hydrocarbon selectivities for the catalytic sample 6 wt. \% Mo/ZSM-5 prepared with ultrasound.

In this regard, the nature and extent of coke deposits after $6 \mathrm{~h}$ on stream were evaluated by Raman spectroscopy and thermogravimetric analysis for the four catalytic samples. Figure 9a shows the Raman spectra of the coked catalysts after MDA, highlighting the D (disordered) and G (graphitic) bands related to hard- and soft-coke, respectively. The D band is associated to the pre-graphitic polyaromatic hydrocarbon deposits whereas $\mathrm{G}$ band reveals the graphitic nature of the carbonaceous species related to the Mo carbides. The rate between $\mathrm{D}$ and $\mathrm{G}$ band intensities allows gaining insight into the catalytic performance of the samples. The disordered coke tends to be formed at the acid sites within the zeolite pores and may affect selectivity, whereas the graphitic coke is normally found at the zeolite surface and deposited over the active Mo carbide species, thus, affecting activity. As a result, low metal dispersions are normally associated with enhanced graphitic coking. 

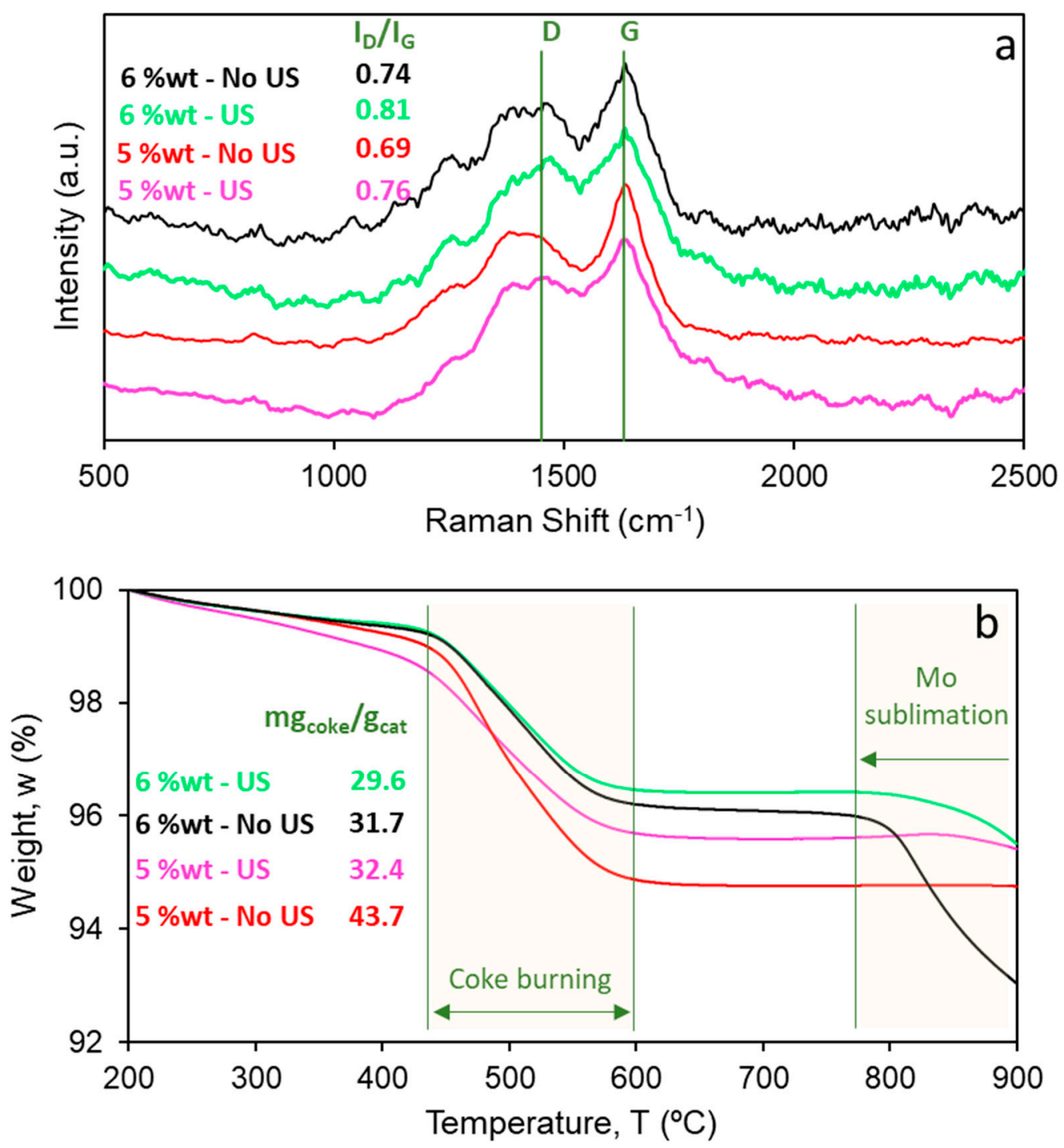

Figure 9. (a) Raman spectra of coked Mo/ZSM-5 samples after MDA showing the rate between the maximum intensity of the disordered and graphitic coke bands $\left(\mathrm{I}_{\mathrm{D}} / \mathrm{I}_{\mathrm{G}}\right)$; (b) thermogravimetric analysis of Mo/ZSM-5 coked samples showing the relative amount of coke deposits generated under MDA operation. Time on stream (TOS): $6 \mathrm{~h}$. Operational conditions: $1500 \mathrm{~mL} / \mathrm{g}_{\text {cat }} \mathrm{h}, \mathrm{CH}_{4}: \mathrm{N}_{2}=80: 20, \mathrm{~T}=700{ }^{\circ} \mathrm{C}, \mathrm{P}=1$ bar.

Figure 9a reveals that the samples prepared under ultrasound irradiation showed higher $\mathrm{I}_{\mathrm{D}} / \mathrm{I}_{\mathrm{G}}$ rates regardless their metal loading, which agrees with their improved Mo dispersion. Furthermore, Figure $9 \mathrm{~b}$ confirms the lower coke selectivity attained for the ultrasound-assisted samples during the MDA process with respect to the conventional catalysts. In addition, it is observed that the $6 \mathrm{wt}$. \% Mo samples produce less coke deposits. This may be attributed to the lower ion exchange of the $5 \mathrm{wt}$. \% Mo samples between the cationic Mo species of the metal precursor and the Brønsted acid sites of the zeolite, leading to higher remaining acidity for the catalysts with lower metal loading. The higher acidity is expected to enhance the formation of polyaromatic hydrocarbon deposits. Figure $9 b$ also reveals that eventual Mo species sublimation may take place for the higher loading samples at temperatures above $800^{\circ} \mathrm{C}$. Therefore, metal loading loss between consecutive MDA $\left(700^{\circ} \mathrm{C}\right)$-regeneration $\left(550^{\circ} \mathrm{C}\right)$ cycles is not expected. To confirm that, the Mo loading of the spent catalyst after regeneration at $550{ }^{\circ} \mathrm{C}$ under $\mathrm{N}_{2}: \mathrm{O}_{2}=95: 5$ atmosphere was determined by SEM-EDX. The obtained values were $4.8 \pm 0.7,5.0 \pm 0.7,5.7 \pm 0.7$, and $5.7 \pm 0.7$ for the $5 \mathrm{wt} . \%$ US, 5 wt. $\%$ No US, 6 wt. $\%$ US, and 6 wt.\% No US catalysts, respectively. Compared 
to the metal loadings obtained for the fresh samples, the average metal loss among the different samples after a MDA-regeneration cycle remains below $2.7 \%$.

Summarizing the previous results, they reveal that: (i) it is important to maintain the trade-off between the metal loading and the dispersion of metal species on the zeolite support for an effective catalytic activity and (ii) ultrasound helps to improve such dispersion promoting the cationic-exchange at the acidic sites of the zeolite. Nevertheless, despite the methane conversion differences observed during the induction period among US and no-US samples, the bulk catalytic activity after $4 \mathrm{~h}$ on stream was quite similar for all samples. The highest benzene yield and total hydrocarbon yield attained were roughly $3.7 \%$ and $7.8 \%$, respectively, using the $6 \mathrm{wt} . \%$-US sample.

The above results show that the sole enhanced molybdenum dispersion achieved by ultrasound does not suffice to obtain a significantly higher catalytic productivity. The experimental results reported in this work were compared with the literature results on various Mo/ZSM- 5 catalysts for MDA. Table 4 compares the methane conversion and aromatics yield values attained along this study against the benchmarking results reported under the same experimental conditions, i.e., $700{ }^{\circ} \mathrm{C}, 1 \mathrm{~atm}$ and $1500 \mathrm{~mL} / \mathrm{g}_{\text {cat }} \mathrm{h}$.

Table 4. Comparison of $6 \%$ Mo/ZSM- 5 catalyst prepared with ultrasound with previous MDA results reported in literature on fixed beds of $5-6 \% \mathrm{Mo} / \mathrm{ZSM}-5$ prepared by different methods. Operational conditions: $\mathrm{T}=700{ }^{\circ} \mathrm{C}, \mathrm{P}=1 \mathrm{~atm}, 1500 \mathrm{~mL} / \mathrm{g}_{\text {cat }} \mathrm{h}, \mathrm{Si} / \mathrm{Al}=10-15, \mathrm{TOS}=5 \mathrm{~h}$.

\begin{tabular}{ccc}
\hline Reference & $\mathbf{X}_{\mathbf{C H} 4(5 \mathbf{h})}(\mathbf{\%})$ & $\mathbf{Y}_{\mathbf{C 2 +}(5 \mathbf{h})}(\mathbf{\%})$ \\
\hline Julian et al. [28] & 12.7 & 9.0 \\
Han et al. [7] & 8.1 & 7.5 \\
Tan [37] & 10.5 & 8.4 \\
Martinez and Penis [38] & 8.2 & 6.0 \\
Liu et al. [39] & 11.2 & 6.9 \\
Song et al. [26] & 11.7 & 8.7 \\
Liu et al. [40] & 13.3 & 9.4 \\
Xu et al. [41] & 5.5 & 5.0 \\
6 wt.\%-US (This work) & 13.0 & 7.8 \\
\hline
\end{tabular}

Our best methane conversion results are among the highest reported ones after $5 \mathrm{~h}$ on stream. However, slightly lower overall yield to $\mathrm{C}_{2+}$ products are obtained with respect to those reported by e.g., Julian et al. [28] and Liu et al. [40]. Specifically, the Mo/ZSM-5 catalyst prepared by Julián et al. [28] under supercritical solvothermal synthesis under reduced conditions provided the best long-term aromatics yield among all results in literature ( $9.0 \%$ also after $15 \mathrm{~h}$ on stream). As the authors claim, they were able to promote the catalytic activity by preparing atom-like dispersed Mo species within the zeolite pores without any aggregation at the external surface of the zeolite.

\section{Materials and Methods}

\subsection{Materials}

The raw materials used for the preparation of Mo/ZSM- 5 catalysts were ammonium heptamolybdate $\left(\left(\mathrm{NH}_{4}\right)_{6} \mathrm{Mo}_{7} \mathrm{O}_{24} \cdot \mathrm{H}_{2} \mathrm{O}\right.$, Sigma-Aldrich, St. Gallen, Switzerland) and commercial $\mathrm{NH}_{4}$-ZSM-5 zeolite $\left(\mathrm{SiO}_{2} / \mathrm{Al}_{2} \mathrm{O}_{3}=23\right.$, Alfa Aesar, Haverhill, MA, USA) as metal precursor and catalytic support, respectively. The $\mathrm{NH}_{4}-\mathrm{ZSM}-5$ zeolite was calcined in air, prior to the metal loading, at $560{ }^{\circ} \mathrm{C}$ during $4 \mathrm{~h}$ in order to get the $\mathrm{H}-\mathrm{ZSM}-5$ form.

\subsection{Catalysts Preparation}

An ultrasound-assisted ion-exchange method was employed to incorporate the molybdenum precursor into the H-ZSM-5 zeolite. An aqueous solution of ammonium heptamolybdate was prepared with a concentration of 0.09 and $0.11 \mathrm{M}$ to achieve a metal loading of 5 and 6 wt. \% Mo, respectively. Zeolite H-ZSM- 5 was added into this solution and 
stirred until a homogeneous solution was obtained. A liquid-solid ratio $\left(\mathrm{L} / \mathrm{S}, \mathrm{mL} \cdot \mathrm{g}^{-1}\right)$ of 50 was used for the preparation of all catalysts.

The suspension composed by the metal precursor and the zeolite powder was transferred into a custom-made double-wall glass cylinder without the top and bottom plate (Figure 10). The cylinder has an internal diameter of $53 \mathrm{~mm}$, an outer diameter of $83 \mathrm{~mm}$, and a height of $200 \mathrm{~mm}$. This cylinder was placed on the top of a plate transducer, which acted as the bottom of the reactor and worked at a resonance frequency of $91.8 \mathrm{kHz}$. The glass cylinder and transducer were clamped together to allow proper sealing and avoid any solution leakage. A custom-made glass propeller of $30 \mathrm{~mm}$ diameter was used to stir the solution at $80 \mathrm{rpm}$. The solution temperature was achieved via a Haake D8 thermostatic bath and external Pt100 temperature probe immersed in the solution. The ion-exchange process was carried out at $60^{\circ} \mathrm{C}$ for $120 \mathrm{~min}$. At the end of the process, the samples were filtered, dried in air at $85^{\circ} \mathrm{C}$, and calcined in air (heating ramp: $1^{\circ} \mathrm{C} \cdot \mathrm{min}^{-1}$ ) at $550{ }^{\circ} \mathrm{C}$ for $6 \mathrm{~h}$. Two reference samples were obtained for each metal loading under silent conditions (without ultrasonic irradiation). In total four catalysts were prepared.

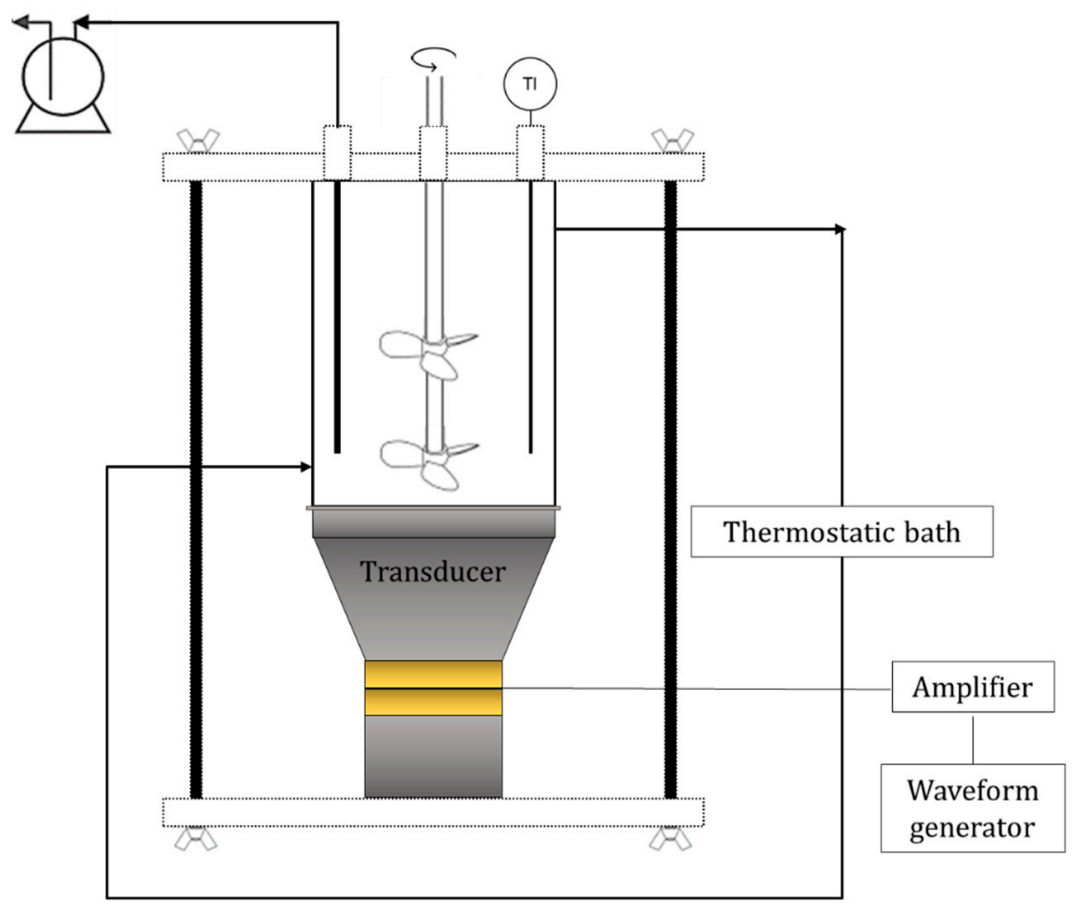

Figure 10. Experimental set-up for the ultrasound-assisted ion-exchange.

\subsection{Catalysts Characterization}

A wavelength dispersive X-ray fluorescence (XRF) spectrometer (Bruker Tiger S8, Billerica, MA, USA) was used to quantify the real concentration of molybdenum present on the zeolite support after the ion-exchange process. The $\mathrm{X}$-ray tube contains a rhodium target anode and works with $1 \mathrm{~kW}$, maximum accelerating voltage of $50 \mathrm{kV}$ and current up to $20 \mathrm{~mA}$. The diffracting crystal and filter used were LiF200 and $\mathrm{Cu} 200 \mu \mathrm{m}$, respectively.

Argon adsorption (Micromeritics ASAP 2020 analyzer, Norcross, GA, USA) was used to characterize the textural properties of the catalysts. The specific surface area was calculated using the BET equation whereas the pore volume was evaluated at $\mathrm{P} / \mathrm{P}_{0}=0.01$.

XRD was carried out to identify the phase structure of the catalysts and changes of the parent zeolite by the addition of molybdenum and the ultrasonic irradiation. The measurement was conducted on a Bruker D8 Advance diffractometer (Billerica, MA, USA) using $\mathrm{Cu} \mathrm{K} \alpha$ radiation in the range of $5-50^{\circ}$ with an angular step size of $0.015^{\circ}$.

Raman spectroscopy measurements were performed to identify the presence and coordination of molybdenum species in the catalyst with an Alpha 300 Raman spectrometer 
(WITec, Ulm, Germany) using a $532 \mathrm{~nm}$ laser source and CCD camera as the detector. The selected laser power and integration time were $8 \mathrm{~mW}$ and $2 \mathrm{~s}$, respectively.

Thermogravimetric analysis (TGA) was performed to determine the amount of coke formed during the MDA reaction. Analyses were carried out in a Q5000SA (TA instruments, New Castle, DE, USA) using a temperature ramp of $10{ }^{\circ} \mathrm{C} / \mathrm{min}$ up to $900{ }^{\circ} \mathrm{C}$ under air flow (50 $\mathrm{mL} / \mathrm{min})$.

XPS (Axis Ultra DLD—Kratos Analytical Ltd., Manchester, UK) measurements were conducted to evaluate the atomic distribution at the surface of the catalyst and to gain insight into Mo dispersion and extent of internalization within the zeolite pores.

SEM (Zeiss GeminiSEM 500, Jena, Germany) was used to study the morphology of the catalysts by using a secondary electron detector (SED). A backscattered electron detector (BSED) and EDX were also used to study the dispersion of molybdenum and to determine the concentration of molybdenum loading, respectively. Before characterization, the samples were suspended in ethanol. Then, they were sprayed and dried on the sample holder without any sample coating.

Transmission electron microscopy (TEM) and scanning-TEM (STEM) were performed with a Tecnai F30 (FEI company, Hillsboro, OR, USA) and Titan Low Base 60-300 (FEI company, Hillsboro, OR, USA), respectively, to observe the catalyst structure in detail and evaluate the dispersion of molybdenum on the zeolite external surface. Before characterization, the samples were dispersed in ethanol and one drop of the solution was deposited in a TEM copper grid.

\subsection{Catalysts Testing}

The non-oxidative methane dehydroaromatization (MDA) was selected as the target catalytic process. The four synthesized catalysts were tested for MDA in fixed beds containing $0.5 \mathrm{~g}$ of catalyst placed in a vertical quartz tube (internal diameter: $10 \mathrm{~mm}$ ) located inside an electrical oven. The fixed bed was heated up to $700{ }^{\circ} \mathrm{C}$ under a methane-rich atmosphere $\left(80 \% \mathrm{CH}_{4}-20 \% \mathrm{~N}_{2}\right)$. The reducing atmosphere helps to carburize molybdenum species into active $\mathrm{Mo}_{x} \mathrm{O}_{y} \mathrm{C}_{z}$ and $\mathrm{Mo}_{2} \mathrm{C}$ [40]. Catalytic tests were performed at $700{ }^{\circ} \mathrm{C}$ maintaining the same flow condition and a spatial velocity of $1500 \mathrm{~mL} \mathrm{LTP}_{\mathrm{SP}} \cdot \mathrm{g}_{\mathrm{cat}}{ }^{-1} \cdot \mathrm{h}^{-1}$. Two mass flow controllers (Bronkhorst $0-20 \mathrm{~mL}$ STP $\cdot \mathrm{min}^{-1}$ ) were employed to feed the reactants. The sample temperature was measured and controlled with a thermocouple placed within the core of the fixed bed. The outlet gas composition was analyzed with a gas chromatograph (Thermo Fisher Scientific TRACE1310, Waltham, MA, USA) equipped with one TCD and two FID detectors. The columns employed for the separation of the outlet gases were Shincarbon, Plot Alumina and TR-1.

Methane conversion $\left(\mathrm{X}_{\mathrm{CH} 4}\right)$, hydrocarbon selectivity $\left(\mathrm{S}_{\mathrm{CxHy}}\right)$, and hydrocarbon yield $\left(\mathrm{Y}_{\mathrm{CxHy}}\right)$ were calculated using the Equations (5) to (7).

$$
\begin{gathered}
X_{C H_{4}}=\frac{\dot{n}_{C H 4, \text { in }}-\dot{n}_{C H 4, \text { out }}}{\dot{n}_{C H 4, \text { in }}}=\frac{\dot{V}_{C H 4, \text { in }}-\frac{A_{C H 4, \text { out }} / R F_{C_{4}}}{A_{N_{2, \text { out }}} / R F_{N_{2}}} \times \dot{V}_{N 2, \text { in }}}{\dot{V}_{C H 4, \text { in }}} \\
S_{C_{x} H_{y}}=X \times \frac{\dot{n}_{C_{x} H_{y, \text { out }}}}{\dot{n}_{C H_{4, \text { in }}}-\dot{n}_{C H_{4, \text { out }}}}=X \times \frac{\frac{A_{C_{x} H_{y, \text { out }} / R F_{C_{x} H_{y}}}}{A_{N_{2, \text { out }}} / R F_{N_{2}}} \times \dot{V}_{N 2, \text { in }}}{\dot{V}_{C H 4, \text { in }}-\frac{A_{C_{x} H_{y, \text { out }}} / R F_{C_{x} H_{y}}}{A_{N_{2, \text { out }}} / R F_{N_{2}}} \times \dot{V}_{N 2, \text { in }}} \\
Y_{C_{x} H_{y}}=X_{C H_{4}} \times S_{C_{x} H_{y}}
\end{gathered}
$$

where $\dot{n}_{i}, \dot{V}_{i}, A_{i}$, and $R F_{i}$ correspond to the molar flow, volumetric flow, peak area, and response factor of the species $i$, respectively. The response factor represents the ratio between the response of a detector to a compound (peak area) and the concentration of that compound in a mixture of gases [42]. 


\section{Conclusions}

An ultrasound-assisted ion-exchange synthesis method was used for the preparation of Mo/ZSM- 5 catalysts for their use in non-oxidative methane dehydroaromatization. Characterization results showed that ultrasonic irradiation does not affect the crystalline structure and particle size of the parent zeolite. Nevertheless, the dispersion of molybdenum was improved when ultrasound was applied during the ion-exchange process. The use of ultrasound along Mo/ZSM-5 synthesis led to the partial inhibition of detrimental $\mathrm{MoO}_{3}$ agglomerates formation at the external surface of the zeolite. The irradiated samples presented better final dispersion in terms of amount of mono- or dimeric Mo cationic species anchored at the acid sites of the zeolite pores for a given metal loading. As a result, the $6 \% \mathrm{Mo} / \mathrm{ZSM}-5$ catalyst prepared using ultrasound radiation provided the best methane conversion and hydrocarbons yield $\left(\mathrm{C}_{2+}\right)$ among the tested MDA catalysts $(13.2 \%$ and $7.9 \%$, respectively, after $4 \mathrm{~h}$ on stream). Despite the enhanced molybdenum dispersion, the hydrocarbons productivity was comparable to the traditional Mo/ZSM- 5 catalyst prepared by impregnation and lays far from the $9.0 \%$ aromatics yield after $15 \mathrm{~h}$ on stream obtained for the most stable Mo/ZSM-5 catalyst for MDA reported to date.

Author Contributions: Conceptualization, H.R.-M. and I.J.; methodology, I.J.; software, H.R.-M.; validation, I.J., M.V.L.P., T.V.G. and C.L.; formal analysis, H.R.-M. and I.J.; investigation, H.R.-M.; resources, C.L. and I.J.; data curation, H.R.-M. and I.J.; writing-original draft preparation, H.R.-M.; writing-review and editing, I.J.; visualization, H.R.-M. and I.J.; supervision, M.V.L.P., T.V.G. and C.L.; project administration, T.V.G.; funding acquisition, T.V.G. All authors have read and agreed to the published version of the manuscript.

Funding: This project has received funding from the Europeans Union's Horizon 2020 for research and innovation program under the Marie Sklodowska-Curie grant agreement No 721290 (MSCA-ITN COSMIC). This publication reflects only the author's view, exempting the Community from any liability. Project website: http:/ / cosmic-etn.eu/ (accessed on 31 January 2021). The APC have been waived by the journal.

Data Availability Statement: The data presented in this study are available on request from the corresponding author.

Acknowledgments: CIBER-BBN (initiative funded by the VI National R\&D\&i Plan 2008-2011, Iniciativa Ingenio 2010, Consolider Program, CIBER Actions and financed by the Instituto de Salud Carlos III with assistance from the European Regional Development Fund) and NANBIOSIS ICTS are gratefully acknowledged.

Conflicts of Interest: The authors declare no conflict of interest.

\section{References}

1. Collet, T.S.; Johnson, A.H.; Knapp, C.C.; Boswell, R. Natural gas hydrates: A review, natural gas hydrates-Energy resource potential and associated geological hazards. AAPG Memoir 2009, 89, 146-219.

2. BP Statistical Review of World Energy 2017 (2016). Available online: https:/ / es.slideshare.net/BP_plc/bp-statistical-review-ofworld-energy-2017-76902409 (accessed on 31 January 2021).

3. Horn, R.; Schloegl, R. Methane activation by heterogeneous catalysis. Catal. Lett. 2015, 145, 23-39. [CrossRef]

4. Wong, K.S.; Thybaut, J.W.; Tangstad, E.; Stocker, M.W.; Marin, G.B. Methane aromatisation based upon elementary steps: Kinetic and catalyst descriptors. Micro. Meso. Mat. 2012, 164, 302-312. [CrossRef]

5. Karakaya, C.; Morejudo, S.H.; Zhu, H.; Kee, R.J. Catalytic chemistry for methane dehydroaromatization (MDA) on a bifunctional Mo/HZSM-5 catalyst in a packed bed. Ind. Eng. Chem. Res. 2016, 55, 9895-9906. [CrossRef]

6. Taifan, W.; Baltrusaitis, J. CH4 conversion to value added products: Potential, limitations and extensions of a single step heterogeneous catalysis. Appl. Catal. B Environ. 2016, 198, 525-547. [CrossRef]

7. Han, S.J.; Kim, S.K.; Hwang, A.; Kim, S.; Hong, D.; Kwak, G.; Jun, K.; Kim, Y.T. Non-oxidative dehydroaromatization of methane over Mo/H-ZSM-5 catalysts: A detailed analysis of the reaction-regeneration cycle. Appl. Catal. B Environ. 2019, 241, 305-318. [CrossRef]

8. Tempelman, C.H.L.; Zhu, X.; Hensen, E.J.M. Activation of Mo/HZSM-5 for methane aromatization. Chin. J. Catal. 2015, 36, 829-837. [CrossRef]

9. Olivos-Suarez, A.I.; Szecsenyi, A.; Hensen, E.J.M.; Ruiz-Martinez, J.; Pidko, E.A.; Gascon, J. Strategies for the direct catalytic valorization of methane using heterogeneous catalysis: Challenges and opportunities. ACS Catal. 2016, 6, 2965-2981. [CrossRef] 
10. Kosinov, N.; Uslamin, E.A.; Meng, L.; Parastaev, A.; Liu, Y.; Hensen, E.J.M. Reversible nature of coke formation on Mo/ZSM-5 methane dehydroaromatization catalysts. Angew. Chem. Int. Edit. 2019, 58, 7068-7072. [CrossRef] [PubMed]

11. Ismagilov, Z.R.; Matus, E.V.; Tsikoza, L.T. Direct conversion of methane on Mo/ZSM-5 catalysts to produce benzene and hydrogen: Achievements and perspectives. Energy Environ. Sci. 2008, 1, 526-541. [CrossRef]

12. Ma, S.; Guo, X.; Zhao, L.; Scott, S.; Bao, X. Recent progress in methane dehydroaromatization: From laboratory curiosities to promising technology. J. Energy Chem. 2013, 22, 1-20. [CrossRef]

13. Xu, Y.; Bao, X.; Lin, L. Direct conversion of methane under nonoxidative conditions. J. Catal. 2003, 216, 386-395. [CrossRef]

14. Wang, L.; Tao, L.; Xie, L.; Xu, G.; Huang, J.; Xu, Y. Dehydrogenation and aromatization of methane under non-oxidizing conditions. Catal. Lett. 1993, 21, 35-41. [CrossRef]

15. Sun, K.; Ginosar, D.M.; He, T.; Zhang, Y.; Fan, M.; Chen, R. Progress in Nonoxidative Dehydroaromatization of Methane in the Last 6 Years. Ind. Eng. Chem. Res. 2018, 57, 1768-1789. [CrossRef]

16. Spivey, J.; Hutchings, G. Catalytic aromatization of methane. Chem. Soc. Rev. 2014, 43, 792-803. [CrossRef] [PubMed]

17. Schwach, P.; Pan, X.; Bao, X. Direct Conversion of Methane to Value-Added Chemicals over Heterogeneous Catalysts: Challenges and Prospects. Chem. Rev. 2017, 117, 8497-8520. [CrossRef]

18. Vollmer, I.; Li, G.; Yarulina, I.; Kosinov, N.; Hensen, E.J.; Houben, K.; Mance, D.; Baldus, M.; Gascon, J.; Kapteijn, F. Relevance of the Mo-precursor state in H-ZSM-5 for methane dehydroaromatization. Catal. Sci. Technol. 2018, 8, 916-922. [CrossRef]

19. Vollmer, I.; Mondal, A.; Yarulina, I.; Abou-Hamad, E.; Kapteijn, F.; Gascon, J. Quantifying the impact of dispersion, acidity and porosity of Mo/HZSM-5 on the performance in methane dehydroaromatization. Appl. Catal. A 2019, 574, 144-150. [CrossRef]

20. Tempelman, C.H.; Hensen, E.J. On the deactivation of Mo/HZSM-5 in the methane dehydroaromatization reaction. Appl. Catal B 2015, 176, 731-739. [CrossRef]

21. Vollmer, I.; Linden, B.; Ould-Chikh, S.; Aguilar-Tapia, A.; Yarulina, I.; Abou-Hamad, E.; Sneider, Y.G.; Olivos Suarez, A.I.; Hazemann, J.-L.; Kapteijn, F.; et al. On the dynamic nature of Mo sites for methane dehydroaromatization. Chem. Sci. 2018, 9, 4801-4807. [CrossRef] [PubMed]

22. Kumar, N.; Mäki-Arvela, P.; Hajek, J.; Salmi, T.; Murzin, D.Y.; Heikkilä, T.; Laine, E.; Laukkanen, P.; Väyrynen, J. Physico-chemical and catalytic properties of Ru-MCM-41 mesoporous molecular sieve catalyst: Influence of Ru modification methods. Microporous Mesoporous Mater. 2004, 69, 173-179. [CrossRef]

23. Kumar, N.; Masloboischikova, O.V.; Kustov, L.M.; Heikkilä, T.; Salmi, T.; Murzin, D.Y. Synthesis of Pt modified ZSM-5 and beta zeolite catalysts: Influence of ultrasonic irradiation and preparation methods on physico-chemical and catalytic properties in pentane isomerization. Ultrason. Sonochem. 2007, 14, 122-130. [CrossRef] [PubMed]

24. Kosinov, N.; Coumands, F.J.; Uslamin, E.A.; Wijpkema, A.S.; Mezari, B.; Hensen, E.J. Methane Dehydroaromatization by Mo/HZSM-5: Mono- or Bifunctional Catalysis? ACS Catal. 2017, 7, 520-529. [CrossRef]

25. Sun, C.; Yao, S.; Shen, W.; Lin, L. Highly Dispersed Molybdenum Oxide Supported on HZSM-5 for Methane Dehydroaromatization. Catal. Lett. 2008, 122, 84-90. [CrossRef]

26. Song, Y.; Sun, C.; Shen, W.; Lin, L. Hydrothermal post-synthesis of HZSM-5 zeolite to enhance the coke-resistance of Mo/HZSM-5 catalyst for methane dehydroaromatization reaction: Reconstruction of pore structure and modification of acidity. Appl. Catal. A 2007, 317, 266-274. [CrossRef]

27. Julian, I.; Hueso, J.L.; Lara, N.; Solé-Daura, A.; Poblet, J.M.; Mitchell, S.G.; Mallada, R.; Santamaria, J. Polyoxometalates as alternative Mo precursors for methane dehydroaromatization on Mo/ZSM-5 and Mo/MCM-22 catalysts. Catal. Sci. Technol. 2019, 9, 5927-5942. [CrossRef]

28. Julian, I.; Roedern, M.B.; Hueso, J.L.; Irusta, S.; Baden, A.K.; Mallada, R.; David, Z.; Santamaria, J. Supercritical solvothermal synthesis under reducing conditions to increase stability and durability of Mo/ZSM-5 catalysts in methane dehydroaromatization. Appl. Catal. B 2020, 263, 118360. [CrossRef]

29. Dantsin, G.; Suslick, K.S. Sonochemical Preparation of a Nanostructured Bifunctional Catalyst. J. Am. Chem. Soc. 2000, 122, 5214-5215. [CrossRef]

30. Woo, J.-M.; Seo, J.Y.; Kim, H.; Lee, D.-H.; Park, Y.C.; Yi, C.-K.; Park, Y.S.; Moon, J.-H. CuY zeolite catalysts prepared by ultrasonication-assisted ion-exchange for oxidative carbonylation of methanol to dimethyl carbonate. Ultrason. Sonochem. 2018, 44, 146-151. [CrossRef] [PubMed]

31. Vafaeian, Y.; Haghighi, M.; Aghamohammadi, S. Ultrasound assisted dispersion of different amount of Ni over ZSM-5 used as nanostructured catalyst for hydrogen production via $\mathrm{CO}_{2}$ reforming of methane. Energy Conver. Manag. 2013, 76, $1093-1103$. [CrossRef]

32. Erten-Kaya, Y.; Cakicioglu-Ozkan, F. Effect of ultrasound on the kinetics of cation exchange in NaX zeolite. Ultrason. Sonochem. 2012, 19, 701-706. [CrossRef] [PubMed]

33. Gerzeliev, I.M.; Ostroumova, V.A.; Baskhanova, M.N. Enhancement of Ion Exchange in a FAU Type Zeolite during the Synthesis of an Active and Selective Catalyst for Isobutane Alkylation with Butylenes. Pet. Chem. 2018, 58, 676-680. [CrossRef]

34. Velebna, K.; Horňáček, M.; Jorík, V.; Hudec, P.; Čaplovičová, M.; Čaplovič, L. The influence of molybdenum loading on activity of ZSM-5 zeolite in dehydroaromatization of methane. Microporous Mesoporous Mater. 2015, 212, 146-155. [CrossRef]

35. Li, W.; Meitzner, G.D.; Borry, R.W., III; Iglesias, E. Raman and X-ray Absorption Studies of Mo Species in Mo/H-ZSM5 Catalysts for Non-Oxidative CH4 Reactions. J. Catal. 2000, 191, 373-383. [CrossRef] 
36. Rzhevskii, A.M.; Choi, P.; Ribeiro, F.H.; Gulotty, R.J.; Olken, M.M. Monitoring of molybdenum H-ZSM5 catalyst preparation by in situ ultraviolet Raman spectroscopy. Catal. Lett. 2001, 73, 187-191. [CrossRef]

37. Tan, P. The catalytic performance of Mo-impregnated HZSM-5 zeolite in CH4 aromatization: Strong influence of Mo loading and pretreatment conditions. Catal. Commun. 2018, 103, 101-104. [CrossRef]

38. Martinez, A.; Penis, E. Non-oxidative methane dehydroaromatization on Mo/HZSm-5 catalysts: Tuning the acidit and catalytic properties through partial exchange of zeolite protons with alkali and alkaline-earth cations. Appl. Catal. A Gen. 2016, 515, 32-44. [CrossRef]

39. Liu, H.; Bao, X.; Xu, Y. Methane dehydroaromatization under nonoxidative conditions over Mo/HZSM-5 catalysts: Identification and preparation of the Mo active species. J. Catal. 2006, 239, 441-450. [CrossRef]

40. Liu, H.; Zhou, C.; Zhang, Y.; Kan, Q. Facile synthesis and its high catalytic performance of hierarchical ZSM-5 zeolite from economical bulk silicon oxides. Micro. Meso. Mat. 2018, 260, 116-124. [CrossRef]

41. Xu, Y.; Lu, J.; Wang, J.; Zhang, Z. Mo-based zeolite catalysts and oxygen-free methane aromatization. Prog. Chem. 2011, 23, 90-106.

42. Julian, I.; Ramirez, H.; Hueso, J.L.; Mallada, R.; Santamaria, J. Non-oxidative methane conversion in microwave-assisted structure reactors. Chem. Eng. J. 2019, 377, 119764. [CrossRef] 